\title{
EFFECT OF BONE REGENERATION WITH PLATELETS RICH FIBRIN VERSUS MINERALIZED PLASMATIC MATRIX FOR IMMEDIATE IMPLANT PLACEMENT
}

\author{
Nader Nabil Elbokle *, Omnia Ibrahim Sultan **, Ingy Mohamed Chehata** \\ and Ahmed Mohamed Hossam***
}

\begin{abstract}
Objectives: This study was conducted to assess and compare the effect of platelets rich fibrin (PRF) versus mineralized plasmatic matrix (MPM) as bone regenerative materials during immediate implant placement.
\end{abstract}

Material and Methods: A total of 10 patients with 12 implants have been included in this study, patients were divided into 2 groups. Group I received Mineralized Plasmatic Matrix (MPM), and group II received Platelets Rich Fibrin (PRF) as bone regenerative materials for immediate implant placement. The treatment outcome was evaluated clinically and radiographically at 3 and 6 months of implant placement. Also bone height and bone density were measured radiographically preoperatively, immediate post operatively, at 3 and 6 months postoperatively and statistically analysed.

Results: Statistical analysis showed that bone density increased significantly $(p \leq 0.05)$ at 3 , and 6 months postoperatively in both groups. By comparing the two groups, Group I had statistically significant $(\mathrm{p} \leq 0.05)$ higher bone density scores than Group II at all of the follow up intervals. Regarding the bone height, there was no statistically significant difference $(P \geq 0.05)$ between the two groups at all of the follow up intervals except that group I showed a statistically significant $(P \geq 0.05)$ higher mesial bone height level at 3and 6 months postoperatively accompanied by a statistically significant $(P \geq 0.05)$ higher distal bone level as well at 6 months postoperatively than that of group II.

Conclusion: The use of MPM was more superior to PRF as bone regenerative material for immediate implant placement regarding bone height and bone density.

KEYWORDS: Immediate implant, PRF, MPM, bone regeneration, osteointegration, growth factors, and platelet concentrates.

* Assistant professor of Oral \& Maxillofacial surgery. Department of Oral and Maxillofacial Surgery. Faculty of Oral and Dental medicine, Cairo University, Egypt

** Lecturer of Oral \& Maxillofacial Surgery. October University of Modern Sciences and Art. Egypt

*** Lecturer of Radiology. October University of Modern Sciences and Art.Egypt 


\section{INTRODUCTION}

Dental implants are widely used for replacement of missing or hopeless teeth. Branemark original protocol for implant placement required 6 to 8 months healing period following tooth extraction. ${ }^{(1)}$ With the continuing development of techniques an immediate implant placement protocol was presented, in which implants are placed immediately after tooth extraction. ${ }^{(2)}$ Immediate implant placement has many advantages including reduction of the treatment time and the number of surgical interventions as well as preservation of hard and soft tissues. ${ }^{(3-5)}$ However, a challenge exists with immediate implants due to discrepancy between the implant shape and the socket walls, this challenge raised the need for grafting material to fill the implant- bone gap defect. A variety of grafting materials were introduced to solve the problem including autografts, allograft, xenografts and alloplastic bone grafts with or without barrier membranes. ${ }^{(6)}$

The gap between the implant and bone begin to heal with the formation of fibrin scaffold. This is followed by platelets adherence to this scaffold and subsequent platelet activation. Activated platelets start releasing growth factors which facilitate the healing process and triggers undifferentiated mesenchymal cells to the site. ${ }^{(7,8)}$ This attraction of undifferentiated mesenchymal cells and release of growth factors lead to enhancement of osteogenesis with subsequent acceleration of wound healing implant osseointegration. (9-12) The effect of platelets on the healing cascade and promotion of osseointegration highlighted its use for bony defects.

The regenrative effect obtained by plateletes was first reported in the 70 ' $\mathrm{s}^{(13)}$ nowadays a variety of platelet concentrates are used in oral and maxillofaical surgery to enhance hard and soft tissue healing. Platelet-rich fibrin (PRF) and the mineralized plasmatic matrix (MPM) are two different preparations of platelet concentrates currently used in regenerative dentistry.
PRF is the second generation of platelet concentrate that is composed of fibrin mesh, platelets, cytokines and growth factors. ${ }^{(14)}$ It was introduced for use in oral surgery for the first time by Dohan et al. ${ }^{(15)}$ It is prepared with single centrifugation without the addition of anticoagulant, thus it is strictly autologous which is an advantage over PRP. ${ }^{(16)}$ PRF stimulates the angiogenesis and release many growth factors including platelet derived growth factor (PDGF) insulin-like growth factor and tumour growth factor (TGF) alpha, beta which in turn enhance hard and soft tissue healing. ${ }^{(17)}$ In vitro studies on PRF revealed its ability to enhance cell attachment, proliferation and differentiation of osteoblasts. ${ }^{(18,19)}$ Recently many clinical applications of PRF were advocated in implant dentistry with improved implant stability and enhanced tissues healing. ${ }^{(20-24)}$

The Mineralized Plasmatic Matrix (MPM) is an autologous blood product with high concentrations of platelets and fibrin in a liquid state integrated with a bone graft that can be autogenous, allogeneic bone, xenogenic bone or a bone substitute like synthetic bone. ${ }^{(25)}$ It is a modification of PRP and PRF presented previously by Perisse ${ }^{(26)}$ followed by $\boldsymbol{E l ~ M o h e b}{ }^{(27)}$.

The integration of grafts bone particles inside the fibrin network is a definite advantage of MPM over the autologous growth factors membranes in PRM or PRF. Actually, the bone grafting materials are mixed with the autologous growth factors for MPM production. This gives the MPM appropriate positional stability ${ }^{(26,27)}$ by stabilizing the bone particles, maintaining its shape in the defect. Also entrapment of platelets and leukocytes in its fibrin network leads to acceleration of tissue healing and minimization of bone loss during healing period with prevention of soft tissues ingrowth inside the graft. ${ }^{(28)}$

Several authors have documented the efficiency of MPM in the field of implant dentistry, through the 
improvement of implants osseointegration, stability and minimum bone loss results. ${ }^{29-33)}$

This article focuses on comparing the effect of PRF versus MPM in immediate implant placement in anterior maxillary aesthetic zone.

\section{PATIENTS AND METHODS}

This study was conducted on twelve submerged immediately placed implants for replacement of single root implants. A total number of 10 patients (Seven females and three males) were included in this study. The age ranged from 21 to 48 years old with mean value of 34.5. Patients involved in this study were selected from the Department of Oral and Maxillofacial Surgery, Faculty of Dentistry, October University of Modern Sciences and Arts. The inclusion criteria was the presence of one or more single rooted hopeless teeth at the upper jaw, the teeth were diagnosed as un-restorable and indicated for extraction. The exclusion criteria were the presence of any local or systemic condition interfering with hard or soft tissue healing, inadequate oral hygiene and severe periodontitis. Clinical and radiographic evaluation was carried out for all patients.

\section{Patients Grouping}

Patients were randomly divided into two equal groups:

Group I (five candidates 6 implants): the gap between the implant and the socket wall was grafted with MPM.

Group II (five candidates 6 implants): the gap between the implant and the socket wall was grafted with PRF.

\section{Surgical technique:}

The hopeless tooth was atraumatically extracted with the aid of periotome followed by adequate socket debridement and irrigation. Fig (1)

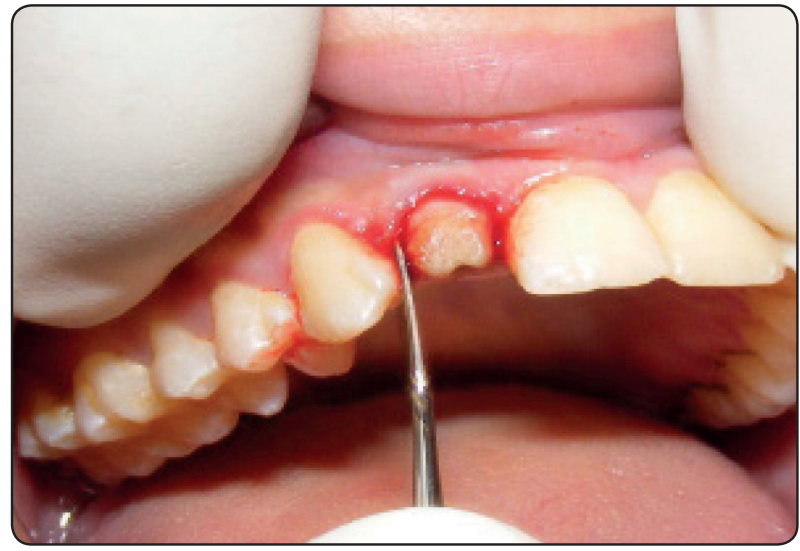

Fig (1): a-traumatic extraction of single rooted tooth using periotome.

The osteotomy site was prepared with sequential drilling to receive the equivalent implant size.

\section{Preparation of PRF\&MPM}

PRF preparation was carried out according to Dohan et al ${ }^{(34)}$ protocol. Venous blood was collected from the antecubital vein. The collected sample was then transferred into $(10 \mathrm{ml})$ sterile test tubes without any anticoagulant. The tubes were placed in the centrifuge machine that was operated to run at 3,000 rpm for 10 minutes. After centrifugation, blood was separated into three distinctive layers: an upper layer of platelet poor plasma, middle layer of platelet rich plasma layer and the bottom layer of red blood cells.

For PRF preparation, the middle layer containing the fibrin clot was held with tissue forceps and separated from the bottom layer with scissors. It was then transferred and gently compressed between two glass slabs to obtain PRF membrane. Fig (2A)

As for the MPM preparation, the plasma rich layer containing fibrin, plasma leukocytes and mesenchymal cells was collected. It was then mixed with particulate bone graft (Beta tri calcium phosphate $\beta$-TCP) and a drop from the patient blood. The mixture was allowed to set for few minutes for polymerization and formation of sticky bone. Fig (2B) 


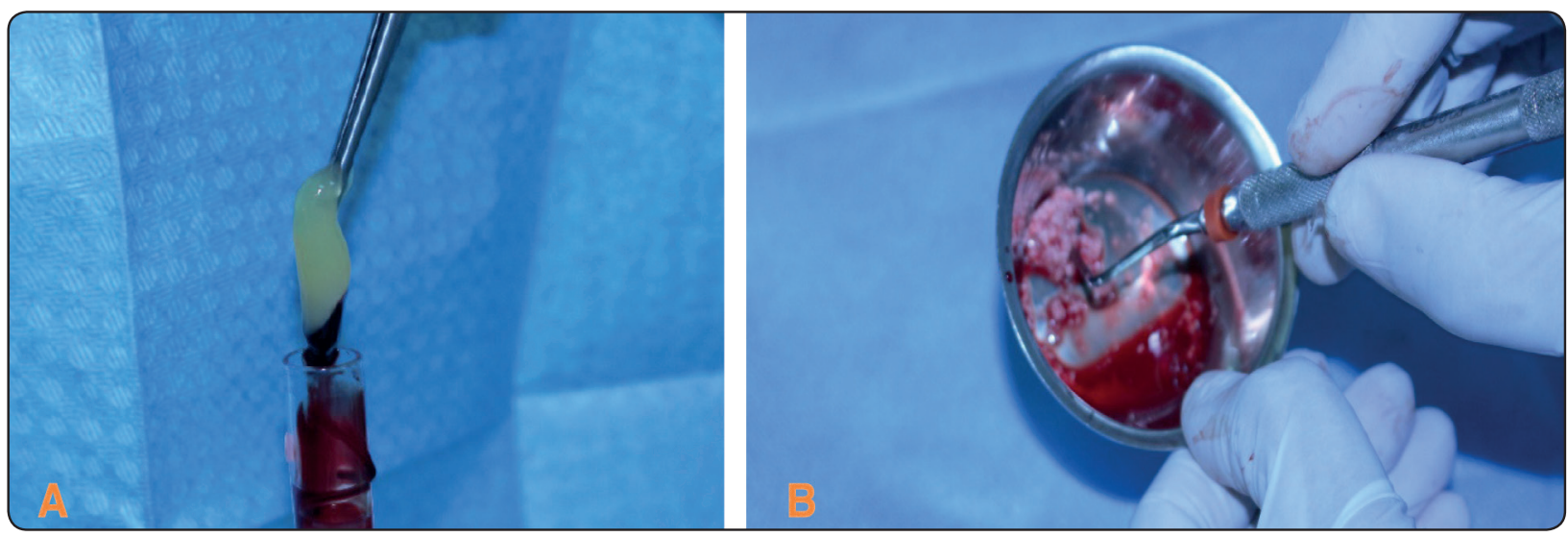

Fig (2): A) The platelet rich fibrin clot ready to be separated from red blood cells coagulum. B) Mixing of platelet rich fibrin layer with particulate bone graft for MPM preparation

Following implant insertion the gap between the implant \& the socket was filled with MPM in group I and PRF in group II. The buccal flap is then advanced and sutured over the implants. Fig (3)

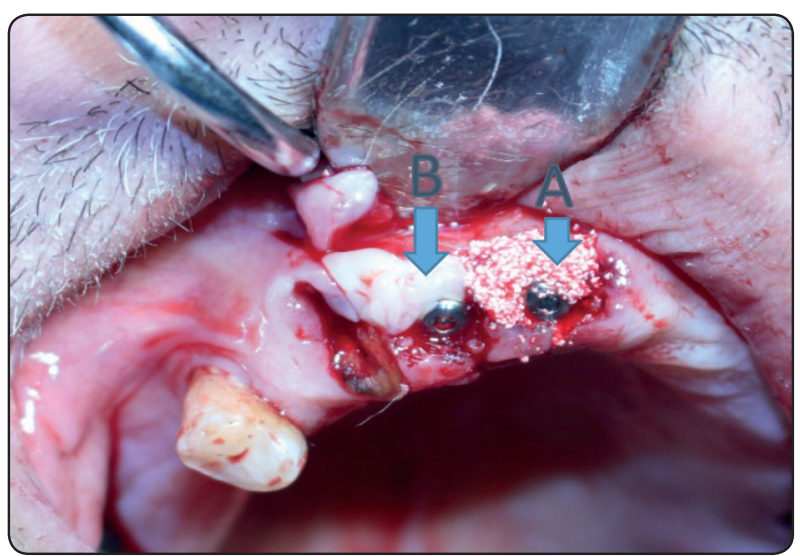

Fig (3): placement of MPM (A) and PRF (B) in the extracted teeth sockets after implants insertion.

\section{Postoperative care}

After surgery, patients were instructed to apply cold packs to minimize post-operative oedema. Mouth wash containing chlorhexidine hydrochloride (Hexitol, Adco) solution was prescribed t.i.d for 2 weeks post- operative along with analgesic antiinflammatory drugs (ibuprofen) and Augmentin antibiotic (amoxycillin + clavulanate potassium, GSK) $1 \mathrm{gm}$ b.i.d for 5 days.After one week patients are recalled for suture removal.

\section{Follow up:}

Patients were recalled on weekly bases during the first month then on monthly bases for clinical and radiographic evaluation. The surgical site was inspected to evaluate the soft tissue healing and implant. Regarding the surrounding bone, it was examined radiographically.

\section{Radiological examination:}

All patients underwent cone beam computed tomography (CBCT) scan before any surgical procedure, for evaluation of bone height and density. Follow up CBCT were made immediately after insertion, 3 months after insertion, and 6 months after insertion. CBCT were evaluated for bone height and bone density at the study intervals.

The radiographic scans were obtained using CBCT Newtom GIANO/VG3- (Quantitative Radiology, Imola, Italy).

Patients were positioned according to the recommendations of the CBCT manufacturer. The midline laser beam of the CBCT system was adjusted to the mid-sagittal plane of the skull. The horizontal laser beam was parallel to the occlusal plane.

Each Patient was scanned a full high resolution scan: Voxel size $0.125 \mathrm{~mm}$ (10 mAs, $90 \mathrm{kVp}, 3 \mathrm{~mA})$ 
and a field of view (FOV) of $80(\mathrm{~mm}) \times 50(\mathrm{~mm})$, $360^{\circ}$ rotation around patients in 3.6-second scan time.

Obtained data was converted into Digital Imaging and Communications in Medicine (DICOM) format, and was imported into the software (Newtom GIANO/VG3-Annex, version 7.2, Imola, Italy) for volumetric analysis. The images were displayed in all 3 orthogonal planes (axial, coronal, and sagittal). Cross-sectional images of the region of interest were generated with a pitch distance of $1 \mathrm{~mm}$ and a slice thickness of $1 \mathrm{~mm}$.

\section{Implant stability measurement:}

The implant stability was measured at 6 months visit before implant loading. This was measured using the resonance frequency analysis via the Osstell ISQ system. A transducer (Smartpeg) was connected to implant to be used with the Osstell device to measure the stability. The stability was evaluated on buccal, palatal, mesial and distal sides of the implant and the mean values of implant stability quotients ISQs were calculated.

\section{Statistical analysis}

The collected data were statistically analysed. The significance of the difference between the preoperative and postoperative data regarding bone height and bone density at the same group was assessed using the Student $\mathrm{T}$ test (paired and unpaired). The two groups were compared to each other using also the Student $\mathrm{T}$ test (paired and unpaired). The statistical analysis was carried out using SPSS ver. 22 software (statistical package for social science on windows 2013). A probability value $\mathrm{p} \leq 0.05$.

\section{RESULTS}

The present study was undertaken to compare the effect of MPM to PRF as bone regenerative material during immediate implant placement. A total of 10 patients with 12 implants have been included in this study with clinical and radiographic assessment for 6 months from the implant placement. No clinical side effects or complications were reported from the use of either material.

\section{Implant stability:}

Mean Implant Stability Quotients (ISQs) of the MPM group I was $70 \pm 10 \mathrm{HU}$, while that of the PRF group II was $68 \pm 11 \mathrm{HU}$ after 6 months of implant placement. There was no statistical significant difference $(P \geq 0.05)$ between implants stability of both groups at this follow up interval. Fig (4)

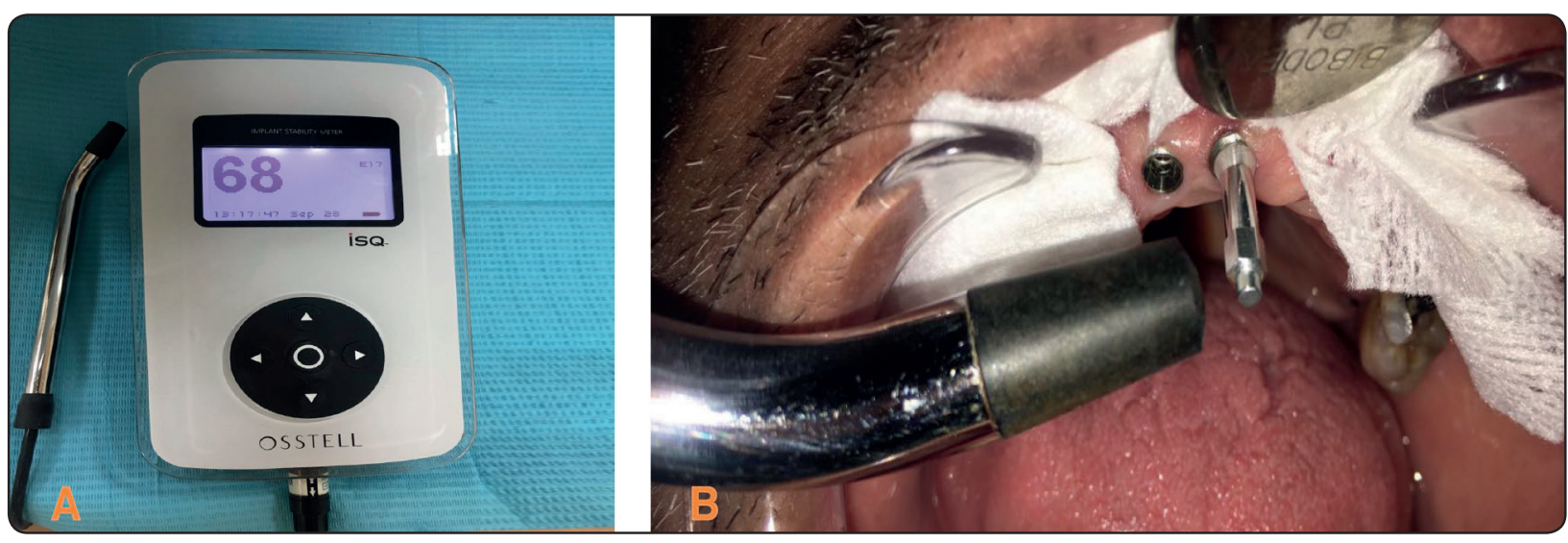

Fig (4): (A,B) ISQ measurement of implant stability using OSSTELL. 


\section{Bone Height:}

Bone height was evaluated using CBCT immediate postoperatively, at 3 and 6 months after implant placement. Comparing the Mean of bone height between the two groups there was no statistically significant difference $(P \geq 0.05)$ between them immediate postoperatively and at 3 months postoperatively except at the distal bone height scores at which MPM (group I) had statistically significant higher bone height level than that of PRF (group II) $(P \leq 0.05)$. As for the 6 months follow up interval, there was no statistical significant $(P \geq 0.05)$ difference between the mean level of bone height between the two groups (buccal and palatal) while the (mesial and distal) scores showed a statistically significant difference $(P \leq$ $0.05)$ between the two groups as group I showed higher bone height scores both mesial and distal than group II. Fig $(5,6)$ (Table 1)

\section{Bone Density:}

The two groups bone densities showed a significant increase $(P \leq 0.05)$ at 3 months postoperatively (Group I=1155.83 $\pm 47.88 \mathrm{HU}$. Group $\mathrm{II}=960.83 \pm 37.16 \mathrm{HU}$ ) in comparison to the immediate implant placement data (Group I=871.00 $\pm 45.88 \mathrm{HU}$. Group II $=805.67 \pm 38.19 \mathrm{HU})$, while at 6 months postoperatively a significant decrease $(P \leq 0.05)$ at the bone density measurements was obvious (Group I=713.83 $\pm 28.52 \mathrm{HU}$.
Group $\mathrm{II}=658.83 \pm 37.16 \mathrm{HU})$ in relation to the 3 months postoperative data. Though the bone densities declined from 3 months to 6 months after implant insertion, yet there was a significant increase $(P \leq 0.05)$ at the bone densities at 6 months postoperatively in comparison with immediate implant placement bone densities.(Table 1,2)

Comparing the two groups, no significant difference was present between them preoperatively while at the immediate postoperative, 3 months postoperative and 6 months postoperative intervals a statistically significant difference was shown between the two groups $(\mathrm{p} \leq 0.05)$. Group I had higher bone density scores than Group II. Fig (7)

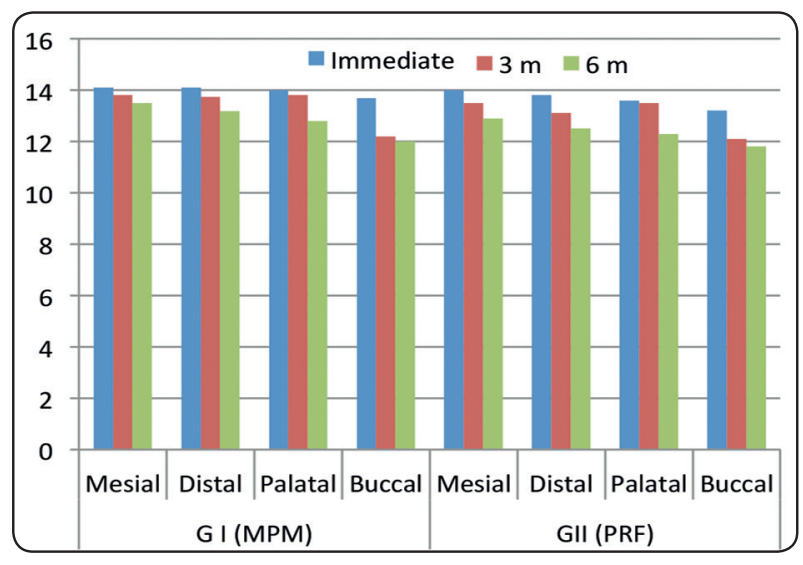

Fig. (5) : Showing a comparison between the mean decreases in Bone height of the two groups at the different follow up intervals. (GI=MPM, GII=PRP)

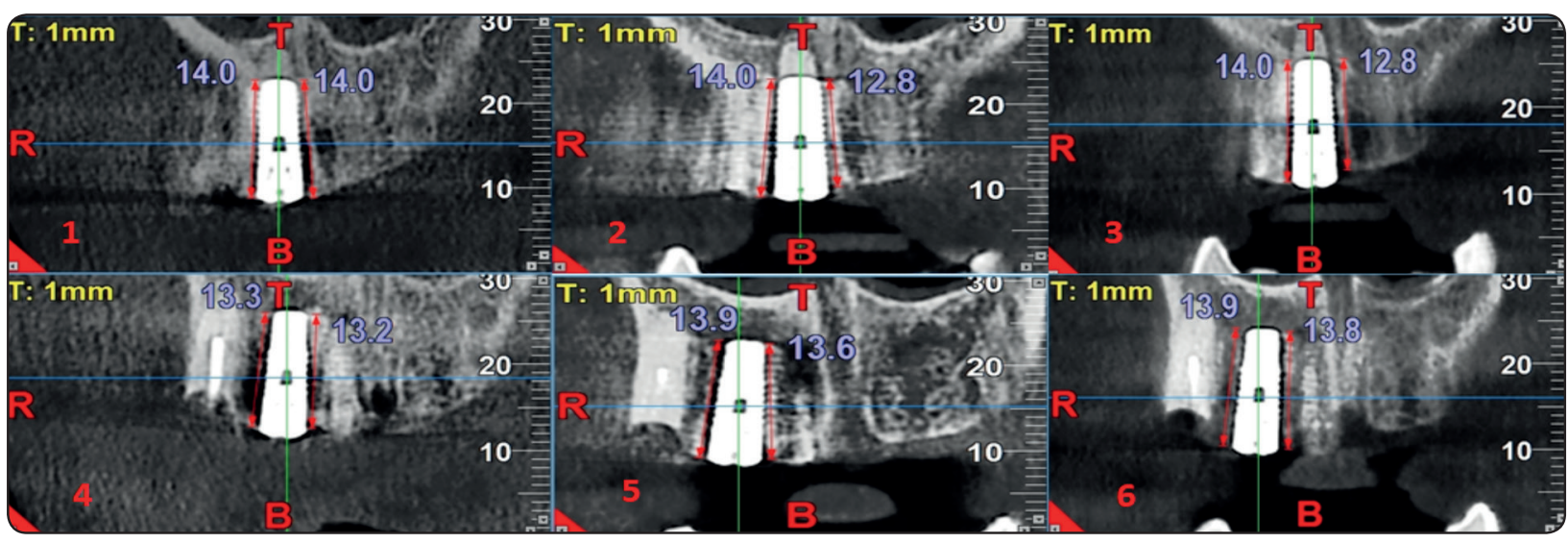

Fig (6) :CBCT Showing Bone height measurements of the two groups at the different follow up intervals. (1,2, 3 MPM group measurements immediate postoperative, at 3 months and 6 months postoperative respectively) (4,5,6 PRF group measurements immediate postoperative, at 3 months and 6 months postoperative respectively) . 
TABLE (1) Comparison of mean bone height scores of the two groups at different follow up intervals.

\begin{tabular}{|c|c|c|c|c|c|c|c|c|c|}
\hline Bone Height & & G I & PM) & & & & RF) & & \\
\hline & Mesial & Distal & Palatal & Buccal & Mesial & Distal & Palatal & Buccal & $P$ value \\
\hline Immediate & $\begin{array}{c}14.1 \\
\pm 0.20\end{array}$ & $\begin{array}{c}14.1 \\
\pm 0.2\end{array}$ & $\begin{array}{r}14.0 \\
\pm 0.3\end{array}$ & $\begin{array}{r}13.7 \\
\pm 0.3\end{array}$ & $\begin{array}{r}14.0 \\
\pm 0.2\end{array}$ & $\begin{array}{r}13.8 \\
\pm 0.1\end{array}$ & $\begin{array}{r}13.6 \\
\pm 0.7\end{array}$ & $\begin{array}{r}13.2 \\
\pm 0.7\end{array}$ & $\begin{array}{l}\text { M: } 0.168, \\
\text { D: 0.021, } \\
\text { P: 0.239, } \\
\text { B: } 0.131\end{array}$ \\
\hline $3 \mathrm{~m}$ & $\begin{array}{r}13.8 \\
\pm 0.3\end{array}$ & $\begin{array}{l}13.75 \\
\pm 0.2\end{array}$ & $\begin{array}{r}13.8 \\
\pm 0.3\end{array}$ & $\begin{array}{r}12.2 \\
\pm 1.4\end{array}$ & $\begin{array}{r}12.0 \\
\pm 1.7\end{array}$ & $\begin{array}{c}13.1 \\
\pm 0.4\end{array}$ & $\begin{array}{r}13.5 \\
\pm 0.8\end{array}$ & $\begin{array}{c}12.1 \\
\pm 1.4\end{array}$ & $\begin{array}{l}\text { M: } 0.198, \\
\text { D: 0.011, } \\
\text { P: } 0.338, \\
\text { B: } 0.920\end{array}$ \\
\hline $6 \mathrm{~m}$ & $\begin{array}{r}13.5 \\
\pm 0.3\end{array}$ & $\begin{array}{c}13.183 \\
\pm 0.4\end{array}$ & $\begin{array}{r}12.8 \\
\pm 1.1\end{array}$ & $\begin{array}{r}10.5 \\
\pm 5.2\end{array}$ & $\begin{array}{r}12.9 \\
\pm 0.4\end{array}$ & $\begin{array}{r}12.5 \\
\pm 0.6\end{array}$ & $\begin{array}{r}12.3 \\
\pm 0.9\end{array}$ & $\begin{array}{r}11.8 \\
\pm 1.7\end{array}$ & $\begin{array}{l}\text { M: 0.022, } \\
\text { D: 0.039, } \\
\text { P: 0.429, } \\
\text { B: } 0.820\end{array}$ \\
\hline $\mathrm{P} 1$ & $\underline{0.002}$ & $\underline{0.003}$ & $\underline{0.122}$ & $\underline{0.025}$ & $\underline{0.004}$ & 0.005 & $\underline{0.093}$ & $\underline{0.091}$ & \\
\hline $\mathrm{P} 2$ & $\underline{0.004}$ & $\underline{0.005}$ & $\underline{0.070}$ & $\underline{0.420}$ & 0.001 & 0.004 & $\underline{0.078}$ & $\underline{0.102}$ & \\
\hline P3 & $\underline{0.002}$ & $\underline{0.001}$ & $\underline{0.032}$ & $\underline{0.043}$ & 0.001 & 0.005 & $\underline{0.051}$ & $\underline{0.088}$ & \\
\hline
\end{tabular}

P1: Immediate VS 3 months, P2: 3 months Vs 6 months, P3: Immediate VS 6 months

TABLE (2) Comparison of mean bone density scores at different follow up intervals of group I (MPM group)

\begin{tabular}{|c|c|c|c|c|}
\hline $\begin{array}{l}\text { GI (MPM) } \\
\text { Bone Density }\end{array}$ & Preoperative & immediate post op & $\mathbf{3 m}$ & $\mathbf{6 m}$ \\
\hline Mean & 525.00 & 871.00 & 1155.83 & 713.83 \\
\hline SD & 46.42 & 45.88 & 47.88 & 28.52 \\
\hline Min & 461.00 & 811.00 & 1094.00 & 664.00 \\
\hline Max & 560.00 & 910.00 & 1200.00 & 743.00 \\
\hline Pre & & $\mathbf{0 . 0 0 0 0}$ & $\mathbf{0 . 0 0 0 0}$ & $\mathbf{0 . 0 0 0 0}$ \\
\hline Post & & & $\mathbf{0 . 0 0 0 0}$ & $\mathbf{0 . 0 0 0 0}$ \\
\hline $\mathbf{3 ~ m}$ & & & & $\mathbf{0 . 0 0 0 0}$ \\
\hline
\end{tabular}

Table (3): Comparison of mean bone density scores at different follow up intervals of group II (PRF group)

\begin{tabular}{|c|c|c|c|c|}
\hline $\begin{array}{c}\text { GII (PRF) } \\
\text { Bone Density }\end{array}$ & Preoperative & immediate post op & $3 \mathrm{~m}$ & $\mathbf{6 m}$ \\
\hline Mean & $\mathbf{5 1 2 . 0 0}$ & $\mathbf{8 0 5 . 6 7}$ & $\mathbf{9 6 0 . 8 3}$ & $\mathbf{6 5 8 . 8 3}$ \\
\hline SD & 39.39 & 38.19 & 37.16 & 37.08 \\
\hline Min & 463.00 & $\mathbf{7 5 7 . 0 0}$ & $\mathbf{9 1 4 . 0 0}$ & $\mathbf{6 1 4 . 0 0}$ \\
\hline Max & 569.00 & $\mathbf{8 6 1 . 0 0}$ & $\mathbf{1 0 1 7 . 0 0}$ & $\mathbf{7 1 5 . 0 0}$ \\
\hline Pre & & $\mathbf{0 . 0 0 0 0}$ & $\mathbf{0 . 0 0 0 0}$ & $\mathbf{0 . 0 0 0 0}$ \\
\hline Post & & & $\mathbf{0 . 0 0 0 0}$ & 0.0000 \\
\hline $3 \mathrm{~m}$ & & & 0.0000 \\
\hline
\end{tabular}




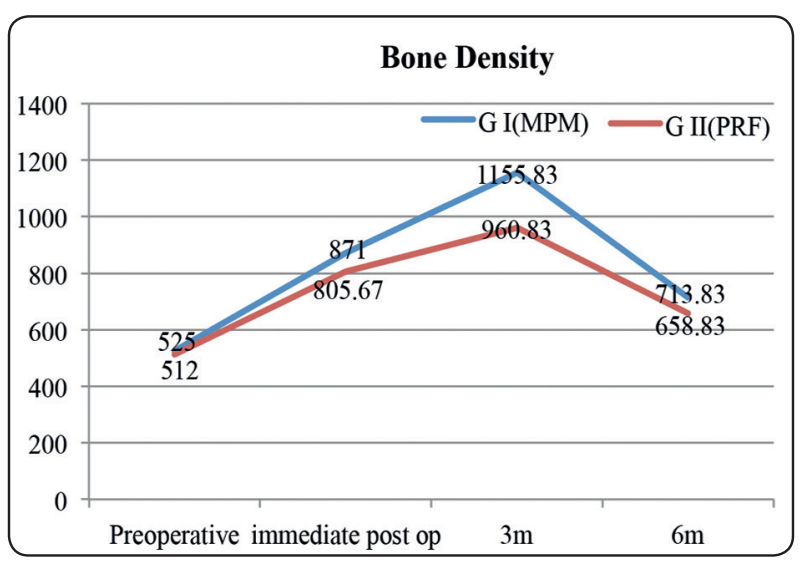

Fig. (7) Line Chart showing the bone density scores of the two groups preoperative, immediate postoperative, 3, 6 months intervals.

\section{DISCUSSION}

Recently autologous blood products rich in growth factors and platelets are progressively used to improve the graft biological characteristics and success rate, an established synergy between the growth factors stimulating action and the target cells attracted into the environment come in the favour of bone regeneration which is created by osteoconductive scaffolds. ${ }^{(31)}$

Platelet concentrates include high concentrations of growth factors such as fibroblast growth factor (FGF),platelet-derived growth factor (PDGF), trans- forming growth factor-b1 (TGF-b1) and b2 (TGF-b2), insulin-like growth factor (IGF) and vascular endothelial growth factor (VEGF), which enhance the healing process. ${ }^{(35)}$ This may cause better bone repair and regeneration. ${ }^{(36)}$

Several techniques for platelet aggregate assembly have been utilized, Choukron"s (15) method for example recently developed platelet aggregation (PRF) by collecting platelet rich fibrin gel and leucocytes using a natural coagulation process. The comparison between the PRF and the PRP goes to the favour of PRF because $1^{\text {st }}$ PRF does not use bovine thrombin or any other exogenous activators in its process of preparation ${ }^{(15)}, 2^{\text {nd }} \mathrm{PRF}$ can be used as a membrane with its fibrin bandage working as a matrix for the acceleration of wound healing, ${ }^{(37)} 3^{\text {rd }}$ PRF natural fibrin architecture could be responsible for a slow release of growth factors and matrix glycoproteins during 7 days ${ }^{(38)} 4^{\text {th }} \mathrm{PRF}$ chair side preparation is fast, inexpensive and simple.

Mineralized Plasmatic Matrix is a homogeneous mixture of two phases: the plasmatic phase and the mineralised phase of bone graft which could be autogenous, allogeneic bone, xenogenic or bone substitute like synthetic bone. Scanning electron microscopy (SEM) reveals that the MPM creates a dense fibrin woven network around the mineral particles. MPM presents many advantages: it is a mouldable mixture, contains the mineral phase which acts as a scaffold for bone cells necessary for bone formation, it also prevents micro and macro movement of the bone graft. As for the fibrin network inside the MPM, it entraps platelets and monocytes to release growth factors and no biochemical additives are needed. ${ }^{(26)}$ The monocytes are very important in bone formation as they regulate the production of BMPs which are highly important proteins in the induction of bone production. ${ }^{(39)}$

In an experimental study conducted by $\boldsymbol{E} \mathbf{l}$ Moheb et $\boldsymbol{a l}{ }^{(30)}$ at which a comparison between the PRF and MPM was done prior to implants placement at sheep heads .They found out that PRF alone was not able to preserve the space necessary for bone formation because it is a gel so it was not able to resist the chewing forces. It is true that PRF gives the necessary extracellular matrix needed by the cells, but since the space was not preserved, the bone could not be built correctly. Therefore, the need to use the bone graft or the bone substitutes to secure the scaffolding was necessary, also mixing the PRF membrane with bone particles didn't give the stability to the bone because they were not linked together. While at the MPM group, since it is a sticky and homogenous mixture. So, once the bone particles or the bone graft were placed on the site, they sticked to the site. 
For bone grafting success, several conditions should be fulfilled such as the graft stability, the space maintenance, the scaffolding and the good wound closure. The platelets concentration does not have the major role in bone regeneration due to its short life time (4 to 8 days). The biomechanical part plays one of the most important roles in bone grafting. The MPM is a natural and autogenous product that can offer bone particles stability. PRF does not give this amount of bone grafting stability, nor the appropriate resistance to chewing forces due to its gel nature.

In the current study, the mean Implant Stability Quotients (ISQs) of the MPM group I was $70 \pm 10 \mathrm{HU}$, while that of the PRF group II was $68 \pm 11 \mathrm{HU}$ after 6 months of implant placement. There was no statistical significant difference $(P \geq 0.05)$ between implants stability of both groups at this follow up interval. Our results concluded that adding PRF or MPM at immediately placed implants favour their stabilities at the follow up intervals. Our findings are in agreement with those found by $\ddot{O}_{n c u ̈}{ }^{(22)}$ who evaluated the PRF applications benefits on the osseointegration process. The use of PRF at implant insertion at his study resulted in statistically significant higher ISQ values which increased continuously over time.

In the current study, we compared the bone density around the implants between the two groups. The MPM group had statistically significant $(\mathrm{p} \leq 0.05)$ higher bone densities than those of PRF at all of the follow up intervals. These finding are in agreement with those of Arafat et al ${ }^{(41)}$ who used PRF added to Bio-Oss in cases of implants accompanied with sinus lift procedure, and also with other clinical studies. ${ }^{(42-44)}$

Regarding the bone height levels around the implants presented in our study, there was no statistically significant difference $(P \geq 0.05)$ between the two groups at all of the follow up intervals except that group I showed a statistically significant $(\mathrm{P} \geq 0.05)$ higher mesial bone height level at 3 and 6 months postoperatively accompanied by a statistically significant $(\mathrm{P} \geq 0.05)$ higher distal bone level as well at 6 months postoperatively than that of group II.

The amount of crestal bone loss present at our study in patients receiving PRF around their immediate implants, is in agreement with Boora ${ }^{(40)}$ who reported lower marginal bone loss associated with PRF use in single staged, immediately dental implants placed in maxillary anterior region.

\section{CONCLUSION}

Based on our findings, we conclude that the MPM and the PRF both have satisfactory results as bone regenerative material for immediate implant placement regarding bone height and bone density. Yet the MPM results were more superior to those of the PRF.

\section{REFERENCES}

1- Branemark PI, Hansson BO, Adell R, Breine U, Lindström J, Hallén O, Ohman A. Osseointegrated implants in the treatment of the edentulous jaw. Experience from a 10-year period. Scand J Plast Reconstr Surg Suppl. 1977; 16:1-132.

2- Vandeweghe S, Hattingh A, Wennerberg A, Bruyn HD. Surgical protocol and short-term clinical outcome of immediate placement in molar extraction sockets using a wide body implant. J Oral Maxillofac Res. 2011; 2(3):e1.

3- Rosenquist B, Grenthe B. Immediate placement of implants into extraction sockets: Implant survival. Int J Oral Maxillofac Implants. 1996;11:205-9.

4- Bhola M, Neely AL, Kolhatkar S. Immediate implant placement: Clinical decisions, advantages, and disadvantages. J Prosthodont. 2008;17:576-81

5- Ortega-Martínez J, Pérez-Pascual T, Mareque-Bueno S, Hernández-Alfaro F, Ferrés-Padró E. Immediate implants following tooth extraction. A systematic review. Med Oral Patol Oral Cir Bucal. 2012;17:e251-61.

6- Sanz M, Lindhe J, Alcaraz J, Sanz-Sanchez I, Cecchinato D. The effect of placing a bone replacement graft in the gap at immediately placed implants: a randomized clinical trial. Clin. Oral Impl. Res. 28, 2017, 902-910 
7- Anitue E, andia I, Ardanza B, Nurden P, Nurden AT. Autologous platelet as a source of protein for healing and tissue regeneration. Thromb haemost 2004; 91: 4-15

8- Cochran Dl. the evidence for immediate loading of implants. JEvid Based Dent Pract. 2006;6: 155-163

9- Anitua EA. Enhancement of osseointegration by generating a dynamic implant surface. J Oral Implantol. 2006;32:72-6.

10- Choukroun J, Diss A, Simonpieri A, Girard MO, Schoeffler C, Dohan SL, et al. Platelet-rich fibrin (PRF): a secondgeneration platelet concentrate. Part IV: clinical effects on tissue healing. Oral Surg Oral Med Oral Pathol Oral Radiol Endod. 2006;101:e56-60.

11- Dohan Ehrenfest DM, Bielecki T, Jimbo R, Barbé G, Del Corso M, Inchingolo F, et al. Do the fibrin architecture and leukocyte content influence the growth factor release of platelet concentrates? An evidence-based answer comparing a pure platelet-rich plasma (P-PRP) gel and a leukocyte- and platelet-rich fibrin (L-PRF). Curr Pharm Biotechnol. 2012;13:1145-52.

12- Fontana S, Olmedo DG, Linares JA, Guglielmotti MB, Crosa ME. Effect of platelet-rich plasma on the peri-implant bone response: an experimental study. Implant Dent. 2004;13:73-8.

13- Ross R, Glomset J, Kariya B, Harker L. A platelet-dependent serum factor that stimulates the proliferation of arterial smooth muscle cells in vitro, Proc.Natl. Acad. Sci. U. S. A. 71 (1974) 1207-1210.

14- Choukroun, J., Diss, A., Simonpieri, A., Girard, M. O., Schoeffler, C., Dohan, S. L., Dohan, A. J., Mouhyi, J., Dohan, D. M., 2006a. Platelet-rich fibrin (PRF): a secondgeneration platelet concentrate. Part IV: clinical effects on tissue healing. Oral surgery, oral medicine, oral pathology, oral radiology, and endodontics 101, e56 60.

15- Dohan D.M , Choukroun J, Diss A, Dohan S.L, Dohan A.J, Mouhyi J, Gogly B.Platelet-rich fibrin (PRF): a secondgeneration platelet concentrate. Part I:technological concepts and evolution, Oral. Surg. Oral. Med. Oral. Pathol. Oral.Radiol. Endod. 101 (2006) e37-44.

16- Passaretti F, Tia M, D'Esposito V, De Pascale M, Del Corso M, Sepulveres R, Liguoro D, ValentinoR, Beguinot F, Formisano P, Sammartino G. Growth-promoting action and growth factor release by different plateletderivatives, Platelets 25 (2014) 252-256.
17- Dohan DM, Choukroun J, Diss A, Dohan SL, Dohan AJ, Mouhyi J, Gogly B. Platelet-rich fibrin (PRF): a secondgeneration platelet concentrate. Part III `: leucocyte activation: a new feature for platelet concentrates? Oral Surg. OralMed. Oral Pathol. Oral Radiol. Endod. 101 (2006) e51-e55.

18- Dohan Ehrenfest DM, Diss A, Odin G, Doglioli P, Hippolyte MP, Charrier JB. In vitro effects of Choukroun's PRF (platelet-rich fibrin) on humangingival fibroblasts, dermal prekeratinocytes, preadipocytes, andmaxillofacial osteoblasts in primary cultures, Oral Surg. Oral Med. Oral Pathol.Oral Radiol. Endod. 108 (2009) 341-352.

19- Wu CL, Lee SS, Tsai CH, Lu KH, Zhao JH, Chang YC. Platelet-rich fibrinincreases cell attachment: proliferation and collagen-related proteinexpression of human osteoblasts, Aust. Dent. J. 57 (2012) 207-212.

20- Hafez WK, Seif SA, Shawky H , Hakam MM . Platelet rich fibrin as a membrane for coverage of immediate implants: Case-series study on eight patients Tanta Dental Journal 12 (2015) 203e210

21- Ahmed ES, Mohammed HE , Ehab AA. The Role of Platelets Rich Fibrin in Immediately Loaded Dental Implants: A Prospective Randomized Controlled Clinical Trial. Journal of American Science 2016;12(10)

22- Öncü E, Alaaddinoğlu EE. The effect of platelet rich fibrin on implant stability. Int J Oral Maxillofac Implants. 2015 May-Jun; 30(3):578-82

23- Ayoub AH, Ramadan OR, Agbor MA. Tissue Engineering, Platelets Concentrates and its Role in Dental Implant Treatment Dental Science 5.1 (2016): 969-980

24- Antonio C ,Giuseppe P ,Antonio B, Mario C ,Massimo A. Platelet-rich fibrin (PRF) in implant dentistry in combination withnew bone regenerative technique in elderly patients International Journal of Surgery Case Reports 28 (2016) 52-56

25- El Moheb M. Growth Factors and fibrin network to improve the particles bone grafting. Case report. International Jornal of oral care and research. 2007;2(3):23-6.

26- Mazzoni L and Périssé J. “Apports de la microscopie électronique à balayage pour la Matrice Plasmatique Minéralisée". La Lettre de la Stomatologie 51(2011).

27- Kim JH., et al. "The use of biodegradable PLGA nanoparticles to mediate SOX9 gene delivery in human mesenchymal stem cells (hMSCs) and induce chondrogenesis". Biomaterials 32.1(2011): 268-278. 
28- Dong-SeokSohn, Bingzhen H, Jin K, Eric Park W, Charles C. Park. Utilization of Autologous Concentrated Growth Factors (CGF) Enriched Bone Graft Matrix (Sticky Bone) and CGF-Enriched Fibrin Membrane in Implant Dentistry. The Journal of Implant \& Advanced Clinical Dentistry. 2015;7(10):11-28

29- EL Moheb M. The Use of Growth Factors Fibrin Network to Enhance Architecture, Mechanical and Biological Aspect of the Graft Particles. I J Pre Clin Dent Res 2014;1(2):41-44 April-June

30- EL Moheb M, Bader A.Z, Mohad G.S, Jin Toriya, Akiko M, Santosh P, Abeer S,Basel B, Nabil K, Mohammad K.A and Naoto O. Mineralized Plasmatic Matrix to Enhance the Bone Grafting Technique. Journal of Hard Tissue Biology 26[3] (2017) 289-292.

31- Erraji S, Soualhi H, Ennibi OK, smaili Z. Management of post-extractional alveolar socket with mineralized plasmatic matrix before implant placement: a case report. Asian Pac. J. Health Sci., 2017; 4(3):220-227.

32- Khadija A, Amina G, Azeddine H, and Jamila K. Effect of Bone Regeneration with Mineralized Plasmatic Matrix for Implant Placement in Aesthetic Zone. Hindawi Case Reports in Dentistry Volume 2017, Article ID 2639564, 5 pages

33- Ayoub AH, Belal SM. Localized Maxillary Ridge Augmentation With Mineralized Plasmatic Matrix for Dental Implant Placement. Int J Prev Clin Dent Res 2017;4(2): 162-164.

34- Dohan DM, Choukroun J, Diss A, Dohan SL, Dohan AJ, Mouhyi J. Platelet-rich fibrin (PRF): a second-generation platelet concentrates. Part II: platelet-related biological features. Oral Surg Oral Med Oral Pathol Oral Radiol Endod 2006;101:e45e50.

35- Lucarelli E, Beccheroni A, Donati D, et al. Platelet derived growth factors enhance proliferation of human stromal stem cells. Biomaterials.2003; 24(18):3095-3100

36- Plachokova AS, Nikolidakis D, Mulder J, Jansen JA, Creugers NH. Effect of platelet-rich plasma on bone regeneration in dentistry: asystematic review. Clin Oral Implants Res 2008; 19(6): 539-45.
37- David M, Ehrenfest D, Marco Del Corso, Diss A, Mouhyi $\mathrm{J}$, and Charrier J. Three-Dimensional Architecture and Cell Composition of a Choukroun's Platelet-Rich Fibrin Clot and Membran Periodontol 2010;81:546-555

38- Dohan Ehrenfest DM, de Peppo GM, Doglioli P, Sammartino G. Slow release of growth factors and thrombospondin-1 in Choukroun's platelet-rich fibrin (PRF): a gold standard to achieve for all surgical platelet concentrates technologies. Growth Factors. 2009; 27(1): 63-6

39- Omar OM, Graneli C, Ekstrom K, Karlsson C, Johansson A, Lausmaa J, et al. The stimulation of an osteogenic response by classical monocyte activation. Biomaterials. 2011;32(8):190-204.

40- Boora P, Rathee M, Bhoria M . Effect of Platelet Rich Fibrin (PRF) on Peri-implant Soft Tissue and Crestal Bone in One-Stage Implant Placement: A Randomized Controlled Trial. Journal of clinical and diagnostic research: JCDR 2015;9, Zc18-21.

41- Arafat SW, Chehata IM, Hossam AH. Sinus floor augmentation with simultaneous implant placement using Bio-Oss with and without PRF: Clinical study. E.D.J. 2017; Vol. 63, No. 1.

42- Simonpieri A, Del Corso M, Sammartino G, Dohan Ehrenfest DM. The relevance of Choukroun's platelet rich fibrin and metronidazole during complex maxillary rehabilitations using bone allograft. Part I: A new grafting protocol. Implant Dent $2009 ; 18: 102-111$.

43- Simonpieri A, Del Corso M, Sammartino G, Dohan Ehrenfest DM. The relevance of Choukroun's platelet rich fibrin (PRF) and metronidazole during complex maxillary rehabilitations using bone allograft. Part II: Implant surgery, prosthodontics and survival. Implant Dent 2009; 18:220-229.

44- Choukroun J, Diss A, Simonpieri A, et al. Platelet-rich fibrin (PRF): A second-generation platelet concentrate. Part V: Histologic evaluations of PRF effects on bone allograft maturation in sinus lift. Oral Surg Oral Med Oral Pathol Oral Radiol Endod 2006 ; 101:299-303. 